\title{
Corrigendum: The impact of stroke on people living in central Uganda: A descriptive study
}

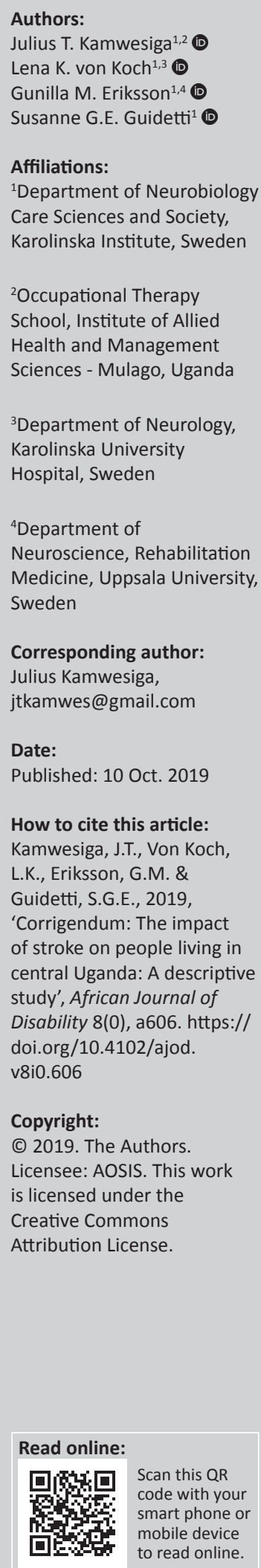

Corresponding author: Julius Kamwesiga, jtkamwes@gmail.com

Date:

Published: 10 Oct. 2019

How to cite this article: Kamwesiga, J.T., Von Koch, L.K., Eriksson, G.M. \& Guidetti, S.G.E., 2019, 'Corrigendum: The impact of stroke on people living in central Uganda: A descriptive study', African Journal of Disability 8(0), a606. https:// doi.org/10.4102/ajod. v8i0.606

\section{Copyright:}

(C) 2019. The Authors. Licensee: AOSIS. This work is licensed under the Creative Commons Attribution License.

In the version of this article published earlier, the surname of the second author, Lena $\mathrm{K}$. von Koch, was inadvertently misspelt as 'von Kock'. The second author's surname should have appeared as 'von Koch' throughout the author list and 'how to cite' information section. This correction does not alter the study's findings of significance or overall interpretation of the study results. The author apologises for any inconvenience caused. 